Check for updates

Cite this: RSC Adv., 2017, 7, 26968

Received 20th November 2016 Accepted 27th March 2017

DOI: $10.1039 / c 6 r a 27055 g$

rsc.li/rsc-advances

\title{
Carbon-containing bone hydroxyapatite obtained from tuna fish bone with high adsorption performance for Congo red
}

\author{
Qifan Peng, Fan Yu, Bicheng Huang and Yaqin Huang (D) *
}

\begin{abstract}
The carbon-containing bone hydroxyapatite ( $\mathrm{CBHA}$ ) has been obtained from tuna fish bone in which the carbon derived from the organics inside the bones acts as a dispersant. The XRD and TEM results indicated that the obtained $\mathrm{HA}$ is on the nanoscale and the $\mathrm{N}_{2}$ adsorption/desorption isotherm showed that $\mathrm{CBHA}$ has mesoporous structure with an enhanced specific surface area $\left(1129.0 \mathrm{~m}^{2} \mathrm{~g}^{-1}\right)$. Moreover, $\mathrm{CBHA}$ as an adsorbent for removal of Congo red (CR) from aqueous solution exhibited high adsorption capacity (329.0 $\mathrm{mg} \mathrm{g}^{-1}$ ) and the adsorption pattern fitted well with Langmuir model $\left(R^{2}>0.96\right)$. The adsorption kinetics of $\mathrm{CBHA}$ for $\mathrm{CR}$ followed the pseudo-second-order model. Thermodynamic parameters, including the Gibbs free energy $(\Delta G)$, enthalpy $(\Delta H)$, and entropy $(\Delta S)$, indicated that the adsorption of $\mathrm{CR}$ onto $\mathrm{CBHA}$ was feasible, spontaneous, and endothermic at the temperature range of 303-323 K. Thus, CBHA as an efficient and low-cost adsorbent can be applied to the treatment of industrial effluents contaminated with $\mathrm{CR}$.
\end{abstract}

\section{Introduction}

Effluent discharged from industries such as textiles, paper, plastic and food is one of the main sources of environmental pollution. ${ }^{1}$ These industrial effluents usually contain synthetic dyes, which are toxic and carcinogenic for aquatic living organisms and humans. However, it's difficult to remove dyestuffs from wastewater in a conventional way since they are non-biodegradable and resistant to light. Several methods have been applied to the treatment of coloured effluents, such as coagulation, photocatalytic degradation, membrane separation, biological treatment, and adsorption. ${ }^{2-6}$ Among these methods, adsorption is one of the most promising methods for its easy operation, high efficiency and low cost.

Hydroxyapatite $\left(\mathrm{HA}, \mathrm{Ca}_{10}\left(\mathrm{PO}_{4}\right)_{6}(\mathrm{OH})_{2}\right)$ has been marked as a potential adsorbent due to its specific structure and adsorption affinity to organics and metal ions. ${ }^{7,8}$ In the last decades, researchers have paid much efforts to synthesize hydroxyapatite. Now there are many methods available, such as sol-gel, hydrothermal processing, co-precipitation, microwave irradiation, electrodeposition and solid state reaction. ${ }^{9-14}$ Nevertheless, researchers are still searching for a method that is facile, cheap and timesaving. Kaludjerovic-Radoicic and Raicevic have utilized phosphate ore that contains only $43.3 \%$ apatite to adsorb metal ions. ${ }^{15}$ Considered that HA is one of the main components of natural bone, Fernane et al. have used cleaned human teeth to treat waste

Beijing Laboratory of Biomedical Materials, Beijing University of Chemical Technology, Beijing 10029, China. E-mail: huangyq@mail.buct.edu.cn; Tel: $+86-13911551112$ water. ${ }^{16}$ Dybowska et al. have obtained hydroxyapatite from meat and bone meal. ${ }^{17}$ Fish bone, which is the waste from fish industry, could be a more available and cheaper source to obtain natural hydroxyapatite. ${ }^{18-20}$ Fish bone have been directly used as an adsorbent to treat waste water which result in the lower removal capacity for its impurity compared with pure HA. ${ }^{21}$ Calcination of fish bone is a facile method to prepare pure HA. ${ }^{22}$ However, HA obtained from fish bones by calcination suffers strong aggregation effect, ${ }^{23}$ resulting in poor adsorption performance.

Here, to inhibit the aggregation of HA, we designed the carboncontaining bone hydroxyapatite (CBHA) using tuna fish bone as raw material. A comparison of our work and the prior art is showed in Table 1. The HA in fish bone is in nanosize and attached on collagen. We retained organics in the bone and calcined the bone. Once the fish bone was calcined in the absence of air, the collagen would be converted to carbon so that CBHA don't tends to grow germs during treatment of water polluted by organic dyestuffs. What's more, the carbon would maintain the nanosize of natural hydroxyapatite. The results demonstrate that the obtained HA in CBHA is in nanosize, and CBHA exhibit excellent adsorption performance for Congo red (CR) [1-naphthalene sulfonic acid, 3,3'(4,4'-biphenylenebis(azo))bis(4-amino-)disodium salt] (Fig. 1). Thus, CBHA is a promising adsorbent that is low-cost, easyprepared and high-performance for water treatment.

\section{Experimental method}

\subsection{Materials preparation}

Fish bone was obtained from tuna (Katsuwonus pelamis). As received frozen bones were defrosted at room temperature, 
Table 1 A comparison of our work and the prior art

\begin{tabular}{llll}
\hline Reference & Source & Preparation & Application \\
\hline 15 & $\begin{array}{l}\text { Phosphate } \\
\text { ore deposit }\end{array}$ & None & $\begin{array}{l}\text { Removal of divalent } \\
\text { heavy metal ions }\end{array}$ \\
16 & $\begin{array}{l}\text { Human teeth } \\
\text { Meat and } \\
\text { bone meal }\end{array}$ & $\begin{array}{l}\text { Cleaning } \\
\text { Sterilization and }\end{array}$ & \\
& incineration & \\
21 & Fish bone & Removal of organics & \\
22 & Fish bone & Calcination (air) & \\
Our work & Fish bone & Calcination (no air) & Removal of CR
\end{tabular}<smiles>Nc1c(N=Nc2ccc(-c3ccc(N=Nc4cc(S(=O)(=O)O)c5ccccc5c4S([O])(=O)=O)cc3)cc2)cc(S(=O)(=O)[O-])c2ccccc12</smiles>

Fig. 1 Molecular structure of CR.

separated from flesh manually and then dried in the air. The dried fish bones were pre-carbonized with electric furnace for $1.5 \mathrm{~h}$ and then calcined in a furnace at $900{ }^{\circ} \mathrm{C}$ at a heating rate of $5{ }^{\circ} \mathrm{C} \min ^{-1}$ in air or in a nitrogen atmosphere. The obtained products were BHA and CBHA, respectively. Once the calcination temperature had been reached, the pre-carbonized bones were maintained isothermally for $3 \mathrm{~h}$, and then cooled naturally. To further investigate composition and structure of CBHA, CBHA was calcined again in a furnace at $600{ }^{\circ} \mathrm{C}$ for $9 \mathrm{~h}$ in air to remove the carbon in it. The obtained product was labelled RCBHA.

\subsection{Materials characteristics}

The composition and structure of as-prepared samples were examined by X-ray diffractometer (Rigaku D/max-2500VB2+/ pC), energy dispersive spectrometer (Oxford X-Max), field emission scanning electron microscope (JSF-7500F) and field emission transmission electron microscope (FEI Tecnai G2 F30). $\mathrm{N}_{2}$ adsorption/desorption isotherms were measured on a surface area analyzer (Quantachrome NOVA 1200).

\subsection{Adsorption experiments}

Adsorption of CR dye aqueous solutions has been carried out on BHA and CBHA. The adsorption experiments were performed with batch equilibration method. For the adsorption studies, the optimum adsorbent loading was found to be $2 \mathrm{~g} \mathrm{~L}^{-1}$. Various initial concentrations (in the range of 100 to $900 \mathrm{ppm}$ ) of CR dye in water were used to study the effect of initial dye concentration on the adsorptive removal of Congo red. For kinetics studies of CR adsorption, the supernatant was collected at various time intervals and separated from the sorbent by centrifugation at $10000 \mathrm{rpm}$ for $5 \mathrm{~min}$. All UV-vis spectra were obtained using TU-1810 UV-vis spectrometer. The equilibrium adsorption capacity of the adsorbent for the CR dye was calculated as follows:

$$
q_{\mathrm{e}}=\frac{\left(C_{0}-C_{\mathrm{e}}\right) V}{m}
$$

where $C_{0}\left(\mathrm{mg} \mathrm{L}^{-1}\right)$ and $C_{\mathrm{e}}\left(\mathrm{mg} \mathrm{L}^{-1}\right)$ are the initial and equilibrium concentrations of CR dyes in the solution, respectively, $V$ (L) is the volume of the CR solution and $m(\mathrm{~g})$ is the mass of adsorbent.

\section{Results and discussion}

\subsection{Sample characteristics}

The XRD patterns of BHA, CBHA and RCBHA are shown in Fig. 2. All diffraction peaks are in good agreement with the JCPDS card no. 89-6440, which demonstrate that all three samples are hydroxyapatite in hexagonal phase with lattice parameters, $a=$ $9.4232 \AA$ and $c=6.8833 \AA$. The same sharp peaks at $31.8^{\circ}, 32.2^{\circ}$ and $32.9^{\circ}$ of BHA and RCBHA, corresponding to the (211), (112) and (300) diffraction lines, indicate carbon (about $7 \mathrm{wt} \%$, measured by Thermogravimetric Analyzer, HCT-1) barely changes the crystal structure of hydroxyapatite. The broad patterns of CBHA are caused by the existence of the carbon in CBHA. The (002), (211), (112), (300) and (202) diffraction lines were used to evaluate the mean crystal size of BHA and RCBHA calculated from Scherrer equation. ${ }^{24}$ The estimated crystal sizes of BHA and RCBHA are $71.2 \mathrm{~nm}$ and $36.9 \mathrm{~nm}$, respectively.

The TEM and HRTEM images of BHA, CBHA, and RCBHA are presented in Fig. 3. The particle size of RCBHA (Fig. 3c) is much smaller than that of BHA (Fig. 3a), which is in accord with their SEM results (Fig. 4). The particle size of HA in CBHA should be smaller than that of RCBHA, for one more time of calcination of CBHA to obtain RCBHA. So we can deem that the particle size of HA in CBHA could be smaller than that of BHA. It reveals that carbon which exists in CBHA could effectively restrain the aggregation of HA particles. It is due to the existence of carbon dispersed on HA particles, which maintained the original nanosize of natural hydroxyapatite in fish bone. Fig. 3b shows that carbon particles are distributed on the surface of HA crystals,

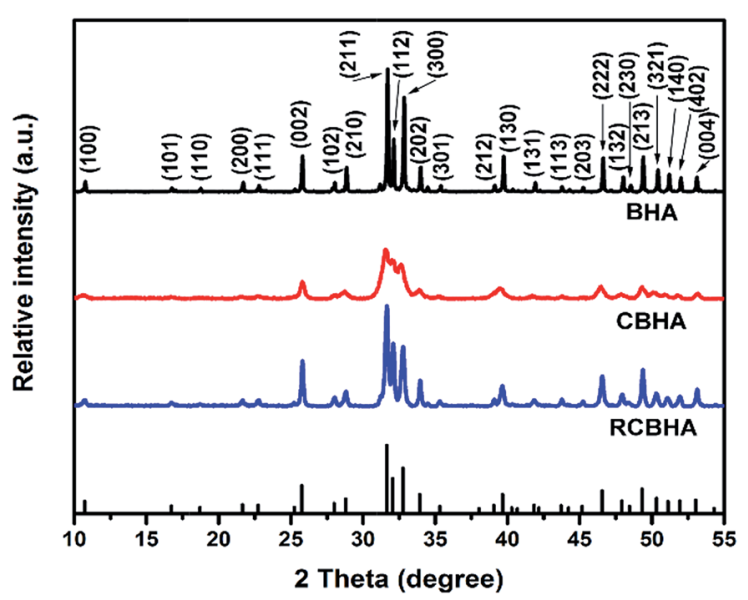

Fig. 2 XRD patterns of $B H A, C B H A$ and RCBHA. 


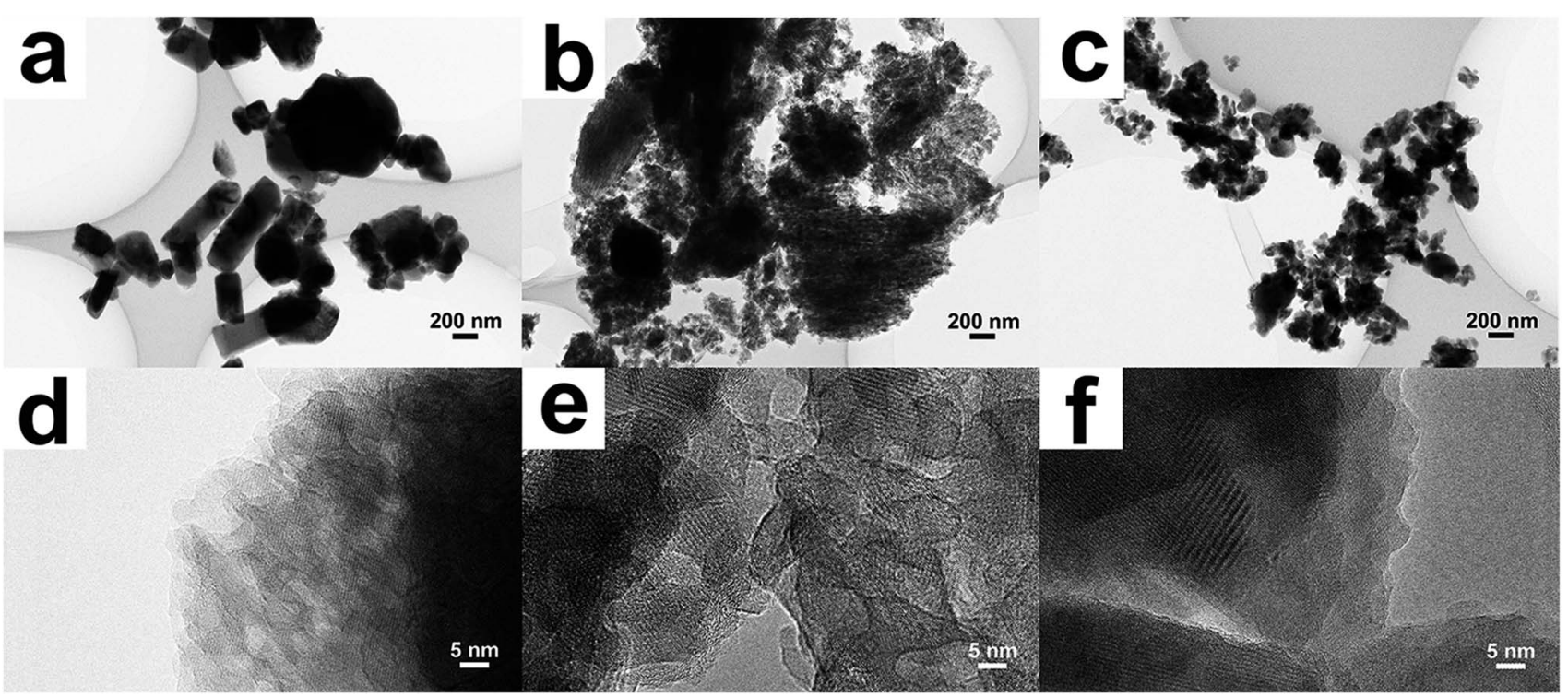

Fig. 3 TEM images of (a) BHA, (b) CBHA and (c) RCBHA; HRTEM images of (d) BHA, (e) CBHA and (f) RCBHA.

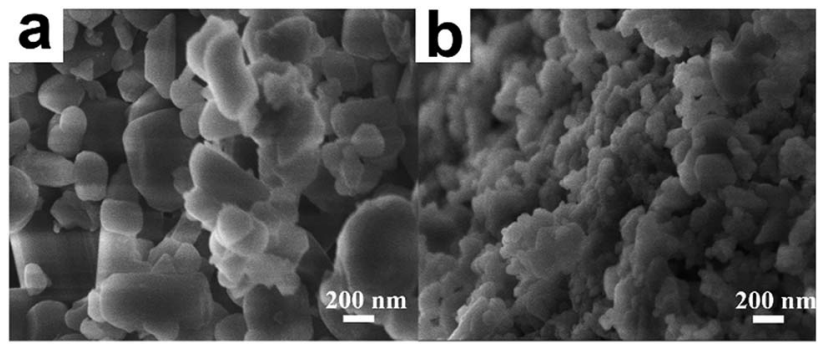

Fig. 4 The SEM images of (a) BHA and (b) RCBHA.

which is confirmed by HRTEM images of three samples (Fig. 3df). Fig. 5 shows the corresponding EDS spectra of BHA and CBHA, confirming that carbon exists in CBHA but rarely in BHA.

The $\mathrm{N}_{2}$ adsorption/desorption isotherms of BHA and CBHA are show in Fig. 6. The BET surface area of BHA and CBHA are measured to be $13.2 \mathrm{~m}^{2} \mathrm{~g}^{-1}$ and $1129.0 \mathrm{~m}^{2} \mathrm{~g}^{-1}$, respectively. The total pore volumes of BHA and CBHA are estimated to be 0.05 $\mathrm{cm}^{3} \mathrm{~g}^{-1}$ and $1.56 \mathrm{~cm}^{3} \mathrm{~g}^{-1}$, respectively. The corresponding pore diameter distribution curves (inset of Fig. 6) indicate the mesoporous structure of both two samples and the average pore
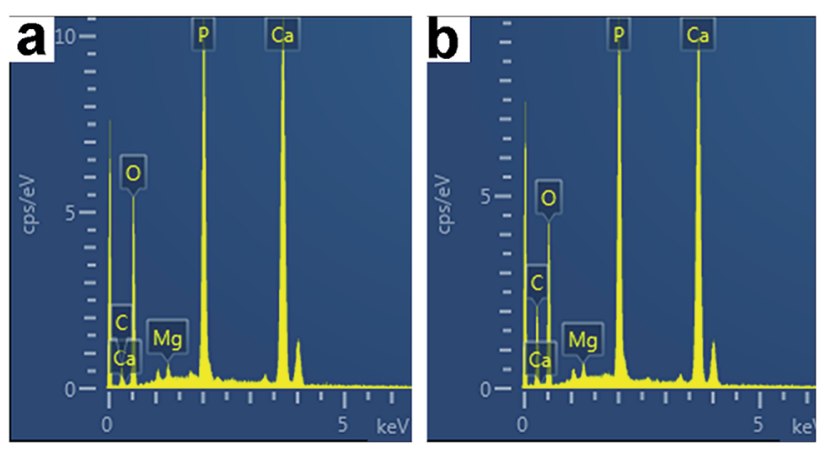

Fig. 5 The corresponding EDS spectra of (a) BHA and (b) $\mathrm{CBHA}$. sizes of BHA and CBHA are $15.1 \mathrm{~nm}$ and $5.5 \mathrm{~nm}$ in diameter, respectively. The results of BET demonstrate that the retained carbon significantly improves the pore structure of CBHA.

\subsection{Adsorption isotherm}

Adsorption isotherms describe the equilibrium between liquid and solid phase. The adsorption isotherm data were fitted using two well-known models, the Freundlich and Langmuir models, which were used to simulate the adsorption isotherm.

The Freundlich adsorption is an empirical equation applicable for heterogeneous surface. The Freundlich isotherm is usually expressed as follows:

$$
q_{\mathrm{e}}=K_{\mathrm{f}} C_{\mathrm{e}}^{1 / n}
$$

where $C_{\mathrm{e}}\left(\mathrm{mg} \mathrm{L}^{-1}\right)$ is the concentration of CR dye at equilibrium, $q_{\mathrm{e}}\left(\mathrm{mg} \mathrm{g}^{-1}\right)$ is the amount of CR dye absorbed at equilibrium, $K_{\mathrm{f}}$

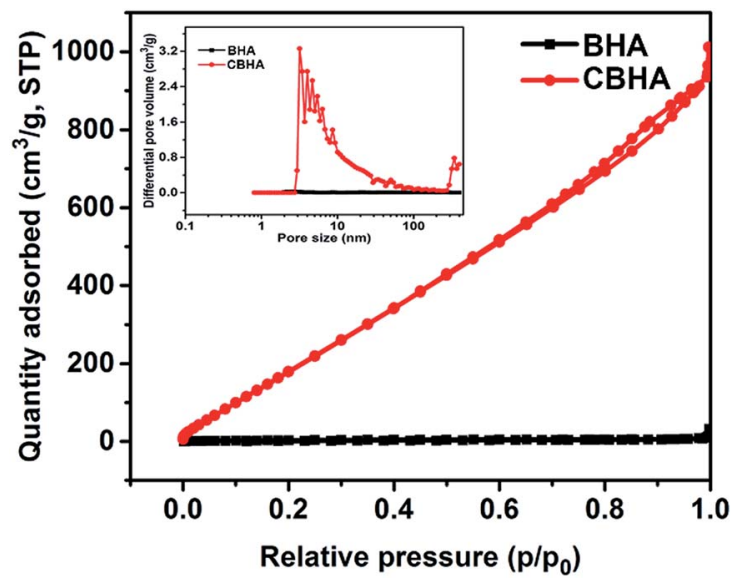

Fig. $6 \quad \mathrm{~N}_{2}$ adsorption/desorption isotherm of $\mathrm{BHA}$ and $\mathrm{CBHA}$. The inset shows the pore diameter distribution curves of $\mathrm{BHA}$ and $\mathrm{CBHA}$. 
(mg $\mathrm{g}^{-1}$ ) and $n$ are Freundlich constants, depicting the adsorption capacity and intensity, respectively.

The Langmuir adsorption isotherm assumes a homogeneous surface with uniform sorption energies and is suitable for monolayer adsorption. Its mathematical form is expressed as follows:

$$
q_{\mathrm{e}}=\frac{q_{\mathrm{m}} b C_{\mathrm{e}}}{1+b C_{\mathrm{e}}}
$$

where $C_{\mathrm{e}}$ and $q_{\mathrm{e}}$ are the same as defined before, $q_{\mathrm{m}}\left(\mathrm{mg} \mathrm{g}^{-1}\right)$ is the theoretical maximum adsorption capacity and $b\left(\mathrm{~L} \mathrm{mg}^{-1}\right)$ is the Langmuir equilibrium constant related to the energy of adsorption.

The parameters and correlation coefficient of two models for BHA and CBHA were listed in Table 2.

Adsorption isotherms for CR by BHA and CBHA are presented in Fig. 7a and b, respectively. According to the correlation coefficient of the two samples, both BHA and CBHA fit well to Langmuir isotherm rather than Freundlich isotherm. The maximum adsorption capacity for removal of Congo red calculated from the Langmuir isotherm model is $329.0 \mathrm{mg} \mathrm{g}^{-1}$ at $300.15 \mathrm{~K}$, about 4 folds that of BHA $\left(79.1 \mathrm{mg} \mathrm{g}^{-1}\right)$, which is corresponding to the results of BET. On the other hand, the essential characteristics of Langmuir isotherm model can be expressed by the equilibrium parameter $R_{\mathrm{L}}$, that is defined as follows:

$$
R_{\mathrm{L}}=\frac{1}{1+b C_{0}}
$$

where $b$ and $C_{0}$ are the same as defined before. Through calculation of $R_{\mathrm{L}}$, the adsorption process can be evaluated to be irreversible $\left(R_{\mathrm{L}}=0\right)$, favourable $\left(0<R_{\mathrm{L}}<1\right)$, linear $\left(R_{\mathrm{L}}=1\right)$ or unfavourable $\left(R_{\mathrm{L}}>1\right)$. Table 1 shows that all the values of $R_{\mathrm{L}}$ are between 0 and 1, implying that BHA and CBHA are favourable adsorbents for removal of Congo red.

\subsection{Adsorption kinetics}

To study the adsorption mechanism, pseudo-first-order and pseudo-second-model have been applied to describe the kinetics of Congo red adsorption onto BHA and CBHA.

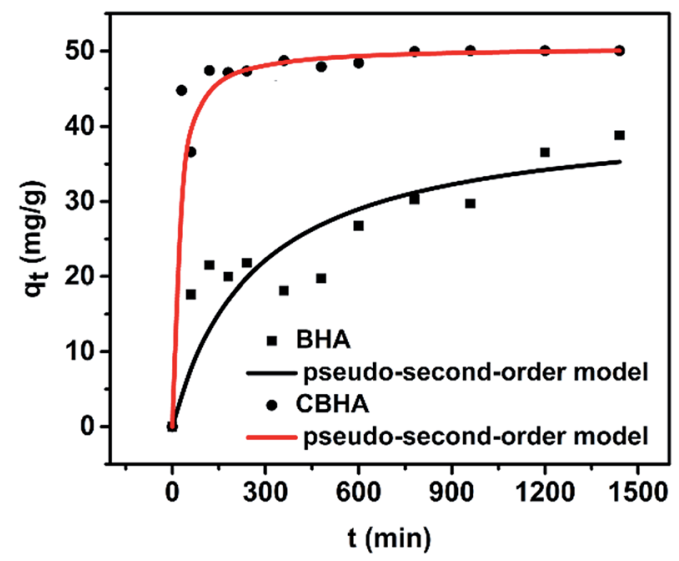

Fig. 8 Adsorption kinetics of CR fitted by pseudo-second-order kinetic model on $\mathrm{BHA}$ and $\mathrm{CBHA}$.

\begin{tabular}{|c|c|c|c|c|c|c|c|}
\hline Adsorbent & \multicolumn{4}{|c|}{ Langmuir isotherm } & \multicolumn{3}{|c|}{ Freundlich isotherm } \\
\hline CBHA & 328.95 & 0.0494 & $0.0220-0.1684$ & 0.9638 & 71.43 & 0.2691 & 0.7416 \\
\hline
\end{tabular}

Table 2 Langmuir and Freundlich parameters of removal of $\mathrm{CR}$ by $\mathrm{BHA}$ and $\mathrm{CBHA}$
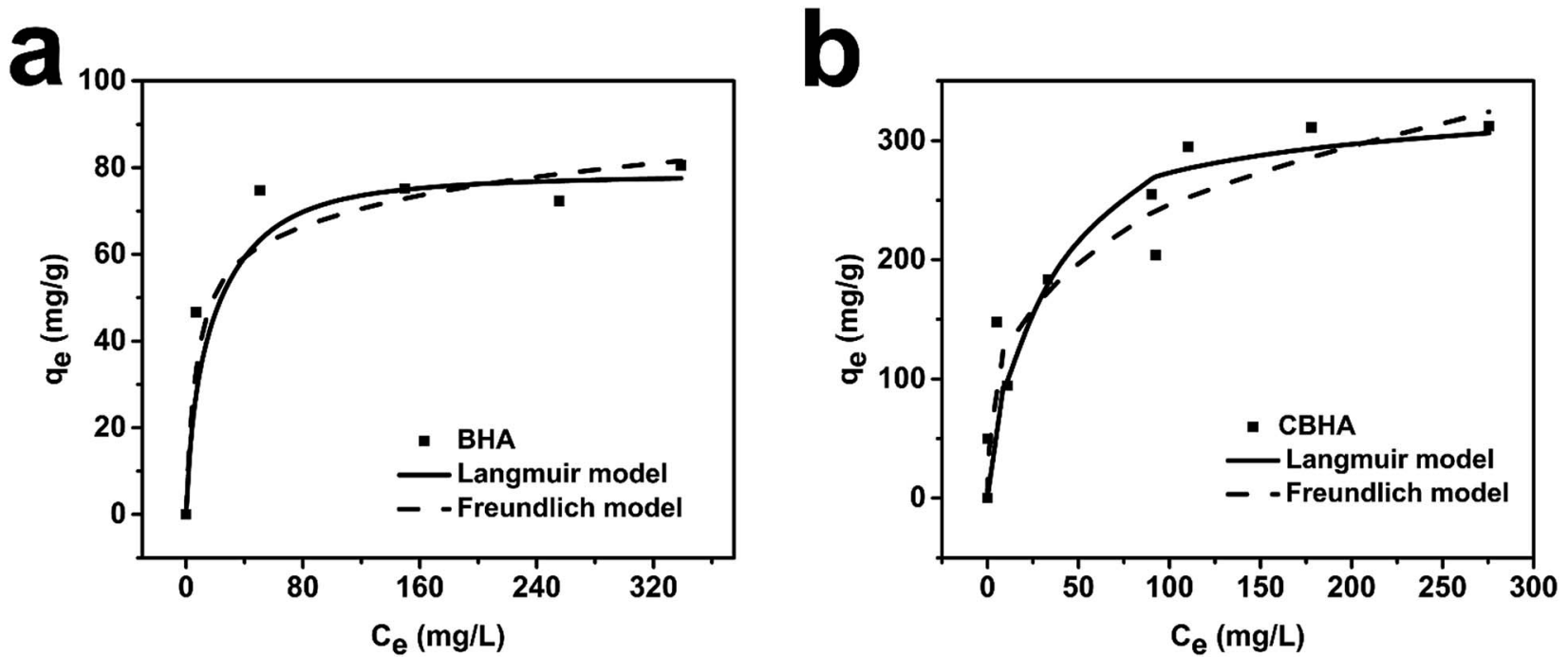

Fig. 7 Adsorption isotherm of CR fitted by Langmuir and Freundlich models on (a) BHA and (b) CBHA. 
Table 3 Comparison of the pseudo-first-order and pseudo-second-order kinetic models on removal of CR by BHA and CBHA

\begin{tabular}{|c|c|c|c|c|c|c|}
\hline Adsorbent & \multicolumn{3}{|c|}{ Pseudo-first-order } & \multicolumn{3}{|c|}{ Pseudo-second-order } \\
\hline CBHA & 0.0048 & 8.85 & 0.6830 & $1.33 \times 10^{-3}$ & 50.58 & 0.9997 \\
\hline
\end{tabular}

The pseudo-first-order model is described as below:

$$
\log \left(q_{\mathrm{e}}-q_{t}\right)=\log q_{\mathrm{e}}-\frac{k_{1} t}{2.303}
$$

The pseudo-second-order model is given by:

$$
\frac{t}{q_{t}}=\frac{1}{k_{2} q_{\mathrm{e}}^{2}}+\frac{t}{q_{\mathrm{e}}}
$$

where $q_{\mathrm{e}}$ and $q_{t}$ are the adsorption capacity $\left(\mathrm{mg} \mathrm{g}^{-1}\right)$ at equilibrium and at any time $t(\mathrm{~min})$, respectively, $k_{1}$ is the pseudofirst-order rate constant $\left(\mathrm{min}^{-1}\right), k_{2}$ is the pseudo-secondorder rate constant $\left(\mathrm{g} \mathrm{mg}^{-1} \mathrm{~min}^{-1}\right)$.

Two kinetic models were tested to depict the adsorption kinetics. As shown in Fig. 8, the adsorption of CR by CBHA reaches the equilibrium in $360 \mathrm{~min}$, while the curve of the adsorption by BHA do not show platform till $1440 \mathrm{~min}$. The kinetic parameters of the two samples calculated from two kinetic models are given in Table 3. The correlation coefficient of pseudosecond-order kinetic model of CBHA is $>0.999$, which is higher than that of pseudo-first-order model (0.6830). Therefore, the results show that the adsorption process did not follow the pseudo-first-order kinetic model but fit well with the pseudosecond-order model. The best fit to pseudo-second-order kinetics indicates that the rate-determining step may be a chemical adsorption which depends on adsorbent and adsorbate.

\subsection{Adsorption thermodynamics}

To study the inherent energetic changes within the adsorption process, the thermodynamic parameters of the adsorption were investigated. The change in the Gibbs free energy $(\Delta G)$, enthalpy $\left(\Delta H_{0}\right)$ and entropy $\left(\Delta S_{0}\right)$ were calculated from the following equations:

$$
\begin{gathered}
k_{0}=\frac{q_{\mathrm{s}}}{C_{\mathrm{e}}} \\
\Delta G=-R T \ln k_{0} \\
\ln k_{0}=-\frac{\Delta H_{0}}{R T}+\frac{\Delta S_{0}}{R}
\end{gathered}
$$

\begin{tabular}{|c|c|c|c|c|c|}
\hline \multirow[b]{2}{*}{ Adsorbent } & \multicolumn{3}{|c|}{$\Delta G\left(\mathrm{~kJ} \mathrm{~mol}^{-1}\right)$} & \multirow{2}{*}{$\begin{array}{l}\Delta H \\
\left(\mathrm{~kJ} \mathrm{~mol}^{-1}\right)\end{array}$} & \multirow{2}{*}{$\begin{array}{l}\Delta S \\
\left(\mathrm{~kJ} \mathrm{~mol}^{-1} \mathrm{~K}^{-1}\right)\end{array}$} \\
\hline & $303 \mathrm{~K}$ & $313 \mathrm{~K}$ & $323 \mathrm{~K}$ & & \\
\hline BHA & -0.97 & -3.61 & -8.78 & 119.33 & 0.4 \\
\hline CBHA & -3.76 & -3.89 & -4.01 & 176.31 & 0.6 \\
\hline
\end{tabular}

Table 4 Thermodynamic parameters for the adsorption of $\mathrm{CR}$ by $\mathrm{BHA}$ and $\mathrm{CBHA}$ where $q_{\mathrm{s}}$ is the amount of CR absorbed per unit mass of CBHA $\left(\mathrm{mg} \mathrm{g}^{-1}\right), k_{0}$ is the adsorption equilibrium constant, $R(8.314 \mathrm{~J}$ $\mathrm{mol}^{-1} \mathrm{~K}^{-1}$ ) is the universal gas constant, and $T(\mathrm{~K})$ is temperature. The thermodynamic parameters are given in Table 4 . Negative $\Delta G$ (ranging from -4.01 to $-3.76 \mathrm{~kJ} \mathrm{~mol}^{-1}$ ) demonstrates that the adsorption of CR by CBHA is spontaneous in the range of 303-323 $\mathrm{K}$ and degree of spontaneity increases with the increasing temperature. Positive $\Delta H$ agrees with the result that adsorption capacity increases with an increase in temperature, which demonstrates the endothermic nature of the adsorption of CR by CBHA. Besides, a positive value of $\Delta S$ means that randomness at the solid-solution interface increases during the adsorption. At all three temperature $|T \Delta S|>|\Delta H|$, demonstrating that the adsorption is dominated by entropy effect rather than enthalpy change. ${ }^{25}$

\section{Conclusions}

Carbon-containing bone hydroxyapatite (CBHA) has been prepared by tuna fish bone via heat treatment in the absence of air. The carbon restrained the aggregation of HA, resulting in maintaining original nanometer size of HA in the fish bone. In addition, CBHA has mesoporous structure with high BET surface area $\left(1129.0 \mathrm{~m}^{2} \mathrm{~g}^{-1}\right)$ and large pore volume $\left(1.56 \mathrm{~cm}^{3}\right.$ $\left.\mathrm{g}^{-1}\right)$. For CBHA adsorption system, the adsorption data fitted well with Langmuir isotherm and the adsorption kinetics followed the pseudo-second-order model. CBHA displays excellent adsorption performances for the removal of CR dye in aqueous solution and the maximum adsorption capacity of CBHA is $329.0 \mathrm{mg} \mathrm{g}^{-1}$ at $303 \mathrm{~K}$. All characteristics indicates that CBHA could be used as an efficient and low-cost adsorbent for water treatment application.

\section{Acknowledgements}

This study is financially supported by the National Natural Science Foundation of China (No. 51272017 and 51432003).

\section{References}

1 H. Hou, R. Zhou, P. Wu and L. Wu, Chem. Eng. J., 2012, 211212, 336-342.

2 V. W. Makene, J. O. Tijani, L. F. Petrik and E. J. Pool, Environ. Monit. Assess., 2016, 188, 11.

3 Y. L. Zhang, C. R. Xie, F. L. Gu, H. H. Wu and Q. Guo, J. Hazard. Mater., 2016, 315, 23-34.

4 J. L. Zhang, H. T. Yu, X. Quan, S. Chen and Y. B. Zhang, Chem. Eng. J., 2016, 301, 19-26. 
5 A. V. Buntic, M. D. Pavlovic, S. S. Siler-Marinkovic and S. I. Dimitrijevic-Brankovic, Water Sci. Technol., 2016, 73, 2231-2236.

6 B. Li, Y. Zhang, X. Zhou, Z. Liu, Q. Liu and X. Li, J. Alloys Compd., 2016, 673, 265-271.

7 C. Srilakshmi and R. Saraf, Microporous Mesoporous Mater., 2016, 219, 134-144.

8 S. Lee, J. An, Y.-J. Kim and K. Nam, J. Hazard. Mater., 2011, 186, 2117-2122.

9 M. Malakauskaite-Petruleviciene, Z. Stankeviciute, G. Niaura, A. Prichodko and A. Kareiva, Ceram. Int., 2015, 41, 7421-7428.

10 E. Iyyappan, P. Wilson, K. Sheela and R. Ramya, Mater. Sci. Eng., C, 2016, 63, 554-562.

11 R. Othman, Z. Mustafa, C. W. Loon and A. F. M. Noor, Procedia Chem., 2016, 19, 539-545.

12 T. Tolga Demirtaș, G. Kaynak and M. Gümüșderelioğlu, Mater. Sci. Eng., C, 2015, 49, 713-719.

13 Q. Zhang, Y. Liu, Y. Zhang, X. Ji, Y. Tan and Q. Liu, Mater. Lett., 2013, 107, 337-339.

14 J. Chen, Z. Wen, S. Zhong, Z. Wang, J. Wu and Q. Zhang, Mater. Des., 2015, 87, 445-449.

15 T. Kaludjerovic-Radoicic and S. Raicevic, Chem. Eng. J., 2010, 160, 503-510.
16 F. Fernane, M. O. Mecherri, P. Sharrock, M. Hadioui, H. Lounici and M. Fedoroff, Mater. Charact., 2008, 59, 554559.

17 A. Dybowska, D. A. Manning, M. J. Collins, T. Wess, S. Woodgate and E. Valsami-Jones, Sci. Total Environ., 2009, 407, 2953-2965.

18 M. Sukul, Y.-K. Min and B.-T. Lee, Mater. Lett., 2016, 181, 156-160.

19 N. H. Herpandi, A. Rosma and W. A. Wan Nadiah, Compr. Rev. Food Sci. Food Saf., 2011, 10, 195-207.

20 M. Boutinguiza, J. Pou, R. Comesaña, F. Lusquiños, A. de Carlos and B. León, Mater. Sci. Eng., C, 2012, 32, 478-486.

21 W. Admassu and T. Breese, J. Hazard. Mater., 1999, 69, 187196.

22 E. A. B. da Silva, C. A. Costa, V. J. Vilar, C. M. Botelho, M. B. Larosi, J. M. Saracho and R. A. Boaventura, Water, Air, Soil Pollut., 2012, 223, 989-1003.

23 B. R. Sunil and M. Jagannatham, Mater. Lett., 2016, 185, 411414.

24 S. Kongsri, K. Janpradit, K. Buapa, S. Techawongstien and S. Chanthai, Chem. Eng. J., 2013, 215-216, 522-532.

25 S. Hokkanen, A. Bhatnagar, E. Repo, S. Lou and M. Sillanpää, Chem. Eng. J., 2016, 283, 445-452. 